\title{
Effective interactions and colloidal stability of bovine $\gamma$-globulin in solution
}

\author{
Stefano Da Vela ${ }^{1}$, Felix Roosen-Runge ${ }^{\ddagger}$, Maximilian W.A. Skoda ${ }^{1 \S}$, Robert M.J. Jacobs $^{3}$, Tilo Seydel ${ }^{2}$, \\ Henrich Frielinghaus ${ }^{4}$, Michael Sztucki ${ }^{5}$, Ralf Schweins ${ }^{2}$, Fajun Zhang ${ }^{1 *}$, Frank Schreiber ${ }^{1}$ \\ ${ }^{1}$ Institut für Angewandte Physik, Universität Tübingen, Auf der Morgenstelle 10, Tübingen D-72076, Germany \\ ${ }^{2}$ Institut Max von Laue - Paul Langevin (ILL), CS 20156, 71 Avenue des Martyrs, Grenoble Cedex 9, F-38042, France \\ ${ }^{3}$ Department of Chemistry, University of Oxford, 12 Mansfield Road, Oxford OX1 3TA, United Kingdom \\ ${ }^{4}$ Jülich Centre for Neutron Science at Heinz Maier-Leibnitz Zentrum (JCNS at MLZ), Forschungszentrum Jülich \\ GmbH, Lichtenbergstrasse 1, Garching D-85747, Germany \\ ${ }^{5}$ European Synchrotron Radiation Facility (ESRF), CS 40220, 71 Avenue des Martyrs, Grenoble Cedex 9, F-38043, \\ France
}

${ }^{\ddagger}$ Present address: Lunds Universitet, Physical Chemistry, Box 124, Lund 221 00, Sweden

${ }^{\S}$ Present address: ISIS, Rutherford Appleton Laboratory, Chilton, Didcot OX110QX, United Kingdom

\author{
*Corresponding author: Dr. Fajun Zhang \\ Email address: fajun.zhang@uni-tuebingen.de \\ Tel: ++49-7071-29-75242, Fax: ++49-7071-29-5110
}

\begin{abstract}
Interactions and phase behavior of $\gamma$-globulins are of fundamental interest in biophysical and pharmaceutical research, as these are among the most abundant proteins in blood plasma. In this work, we report the characterization of the oligomeric state of bovine $\gamma$-globulin, the effective protein-protein interactions and the colloidal stability in aqueous solution as a function of protein concentration and ionic strength. Classical biochemical techniques, such as size exclusion chromatography (SEC) and gel electrophoresis together with small angle X-ray and neutron scattering (SAXS/SANS) were employed for this study. The results show that bovine $\gamma$-globulin solutions are dominated by monomer and idiotype anti-idiotype dimer. Despite the flexibility and highly non-spherical shape of the protein, a simple model with a disk-type form factor and a
\end{abstract}


structure factor of a square-well potential provide a satisfying description of the scattering data. The overall interactions are attractive and the strength decreases with increasing protein concentration, or adding buffer or salts. For higher protein volume fraction (> 7\%), the model would imply a strong particle-particle correlation which does not appear in the experimental data. This mismatch is most likely due to the smearing effect of the conformation change of proteins in solution. The stability of $\gamma$-globulin solutions is highly sensitive to protein concentration, ionic strength and the type of added salts, such as $\mathrm{NaCl}, \mathrm{Na}_{2} \mathrm{SO}_{4}$ and $\mathrm{NaSCN}$. For solutions below $50 \mathrm{mg} / \mathrm{mL}$ and at low ionic strengths $(<0.1 \mathrm{M})$, protein aggregation is most likely due to subpopulations of IgG molecules with attractive patches of complementary surface charge. This effect is reduced for higher protein concentration due to self-buffering effects. For high ionic strength $(>1 \mathrm{M})$, typical salting-in (with $\mathrm{NaSCN}$ ) and salting-out effects (with $\mathrm{NaCl}$ and $\mathrm{Na}_{2} \mathrm{SO}_{4}$ ) are observed. Results are further discussed in comparison with current studies in the literature on monoclonal antibodies.

\section{Introduction}

An accurate biophysical description of protein-protein interactions is important for a more complete understanding of in vivo and in vitro systems. Such interactions determine the phase behavior of protein solutions. Biochemical, medical and pharmaceutical applications often rely on the knowledge of the factors controlling protein stability and aggregation. ${ }^{1,2}$ Another example of the importance of understanding the interactions governing the solubility of proteins is the production of diffraction quality single crystals for macromolecular structural determination by X-ray or neutron diffraction. ${ }^{3,4}$ Furthermore, pathological protein aggregation in vivo is linked to conditions such as Parkinson's and Alzheimer's diseases, ${ }^{5}$ sickle cell anemia, ${ }^{6-} 8$ cryoglobulinemia ${ }^{9}$ and cataract. ${ }^{5,10}$

Small angle X-ray and neutron scattering (SAXS and SANS) techniques are particularly suitable for the study of protein-protein interactions in solution using theoretical models developed initially for simple liquids. ${ }^{11,12,13}$ In many cases Derjaguin-Landau-Verwey-Overbeek (DLVO) theory, widely used in colloid science, describes well the effective protein-protein interactions in the presence of salts by considering the proteins as charged particles. ${ }^{14,15}$ When the predominant interactions are short-range attractive, simple models such as the square well or the sticky hard sphere pair potential ${ }^{16,17}$ can be employed. These potentials allow for a straightforward extraction of thermodynamic parameters such as the second virial coefficient, and for the characterization of the phase behavior of the solution. ${ }^{18}$ When both long-ranged electrostatic repulsion and short-ranged attraction are present simultaneously, a two-Yukawa potential can be employed to describe the effective interactions. ${ }^{19}$ This approach relying on liquid state theory has been rather successful in describing the effective interactions 
in globular protein solutions. In addition, it was also applied to proteins featuring relevant flexibility and highly non-spherical shape, such as antibodies, and to polydisperse systems.. ${ }^{20,21}$ Nevertheless, the limitations inherent to this approach, such as the influence of the conformational heterogeneity of proteins on the precise calculation of structure factors, need also to be taken into account. ${ }^{22,23}$

Antibodies (immunoglobulins) are widely used in research and biotechnology, as well as in medical and pharmaceutical applications. In many cases, concentrated solutions of specific antibodies are required, for example, to achieve the therapeutic dose in a small volume. In particular, Immunoglobulins G (IgG) received much attention due to the crucial role in the human immune system as well as various applications as very specific therapeutic and diagnostic tools. ${ }^{24}$, 25 The total concentration of IgG in blood is normally within 10$25 \mathrm{mg} / \mathrm{mL}$. The concentration of a particular IgG during immune response and in some pathological conditions can reach several tens of $\mathrm{mg} / \mathrm{mL} .^{26}$

The phase transitions of several monoclonal IgGs have been studied under various conditions. ${ }^{26,27}$ The effects of $\mathrm{pH}$, ionic strength as well as the nature of the added salts have been found important for the stability of IgG solutions. ${ }^{28-35}$ Under physiological conditions, liquid-liquid phase separation (LLPS) boundaries of IgGs lie below the solution freezing point. However, the addition of inert polymers such as PEG can induce supplementary "depletion" interactions and alter the phase diagram. It has been found that PEG-induced attraction increases the transition temperatures for LLPS above the freezing point. ${ }^{36}$ Wang et al. systematically studied eight different human $\operatorname{IgGs}^{26}$ and demonstrated experimentally that the identical geometry of different IgG molecules indeed translates into broadly similar coexistence curves describing LLPS for different antibodies. These studies show that extensive knowledge of the phase diagram of antibody solutions is essential for understanding the pathological condensation of IgG in the human body as well as the colloidal stability ${ }^{37}$ of antibodies as drugs.

While monoclonal antibodies have been the focus of recent biophysical studies, few studies on polyvalent mixtures of antibodies have been reported. ${ }^{38,39,40,41,42}$ Polyvalent in this context means containing antibodies directed against different antigens. Antibodies circulating in the blood belong to different classes and subclasses, and moreover they present a repertoire of antigen specificity. Bovine $\gamma$-globulin, the protein product used in the present study, is a polyvalent (thus non-monoclonal) antibody mixture extracted from pooled bovine plasma, consisting of IgG, IgM and IgA. The main component, IgG, is a highly non-spherical protein with four peptide chains (two identical heavy chains of about $55 \mathrm{kDa}$ and two identical light chains of about $20 \mathrm{kDa}$ ) linked by disulfide bonds. The quaternary structure results in a three-lobed overall shape. A considerable structural flexibility has been reported for $\operatorname{IgG} .{ }^{43,44,45,46}$ A polyvalent product such as bovine $\gamma$-globulin contains a mixture of Immunoglobulins G differing mainly in the molecular details (residue composition) in the two lobes containing the antigen binding regions. These differences in residue composition lead to a distribution of isoelectric points for $\gamma$-globulin in the range $5.2<$ pI $<9.2$ with predominant pIs being 


\section{8 and $8.5 .{ }^{47}$}

Bovine $\gamma$-globulin finds various uses in biochemical and biophysical research as standard for molecular weight and protein concentration, ${ }^{48,49,50}$ in studies on the immune response, ${ }^{51}$ as an analog of serum antibodies for different applications ${ }^{52,53,54,55}$ and as a model protein in studies of protein diffusion. ${ }^{39,56}$

It is worth mentioning that a human-derived blood product analogous to bovine $\gamma$-globulin, consisting in higher purity polyvalent immunoglobulins $\mathrm{G}$ is designated intravenous immunoglobulin (IVIG). It is used at high doses and sometimes formulated at high concentrations ${ }^{57}$ to treat immunodeficiencies, autoimmune diseases and other conditions. ${ }^{58}$

Our group has recently studied the global diffusion and internal dynamics of bovine $\gamma$-globulin in crowded aqueous solutions using quasi-elastic neutron scattering. ${ }^{39}$ It is interesting to see that the global short-time diffusion (on the order of nanoseconds) is consistent with predictions for effective spheres even though the branched molecular shape differs considerably from a colloidal sphere. In addition, while it is known that antibodies can form dimers in solution, the neutron backscattering spectroscopy measurements are consistent with the proteins being predominantly monomeric in the concentration range from 100 to $500 \mathrm{mg} / \mathrm{mL}$ due to the absence of any component in the quasi-elastic spectrum which may be associated to dimers.

In this work, we first address the composition and oligomerization state of bovine $\gamma$-globulin using size exclusion chromatography. The purified monomer and dimer are subsequently characterized by SAXS. We further characterize the effective interactions in the original (or unpurified) protein solutions using SAXS and SANS over a large range of concentrations. The stability of $\gamma$-globulin solutions in the presence of typical salts $\left(\mathrm{NaCl}, \mathrm{Na}_{2} \mathrm{SO}_{4}\right.$, and $\left.\mathrm{NaSCN}\right)$ is then interpreted in terms of changes in the effective interactions.

\section{Experimental Section}

\subsection{Materials}

Bovine $\gamma$-globulin (No.G5009) was purchased from Sigma-Aldrich. The purity evaluated by agarose gel electrophoresis is higher than $99 \%$ and the $\mathrm{NaCl}$ content is below $4 \%$. The protein product consists of the following classes of Immunoglobulins: $\operatorname{IgG}(80 \%), \operatorname{IgM}(10 \%)$ and $\operatorname{IgA}(<10 \%)$. Stock solutions of $\mathrm{NaCl}$ (Merck, min.purity 99.5\%), $\mathrm{Na}_{2} \mathrm{SO}_{4}$ (Merck, anhydrous, min.purity 99\%) and $\mathrm{NaSCN}$ (Merck, min.purity $98.5 \%$ ) were prepared at concentrations of $4 \mathrm{M}, 1 \mathrm{M}$ and $5 \mathrm{M}$ respectively. Water of MilliQ grade was used for all solutions. Bovine $\gamma$-globulin stock solutions in the range $100-380 \mathrm{mg} / \mathrm{mL}$ were prepared in water or in a buffer consisting of $20 \mathrm{mM}$ HEPES pH 7.0, $150 \mathrm{mM} \mathrm{NaCl}$ and $2 \mathrm{mM} \mathrm{NaN}_{3}$; the protein concentration was assessed after complete dissolution. Protein solutions for further UV-visible spectroscopy and X-ray scattering experiments were prepared by diluting the stock solutions, either in a buffer consisting of $20 \mathrm{mM}$ HEPES pH $7.0,150 \mathrm{mM} \mathrm{NaCl}$, water or aqueous salt solutions. For neutron scattering experiments, both proteins and salts 
were dissolved in $\mathrm{D}_{2} \mathrm{O}$.

\subsection{UV-visible spectroscopy}

UV-visible spectroscopy was used both to assess $\gamma$-globulin concentration and to characterize the stability of $\gamma$-globulin solutions, using a Cary $50 \mathrm{UV}$-Vis spectrophotometer. Protein concentrations were determined by measuring UV absorption at $280 \mathrm{~nm}$ after baseline correction, using as absorption coefficient $\mathrm{E}_{280}=1.4 \mathrm{mg}^{-}$

${ }^{1} \cdot \mathrm{mL} \cdot \mathrm{cm}^{-1} \cdot{ }^{59}$ The stability of protein solutions as a function of $\mathrm{NaCl}$ and $\mathrm{Na}_{2} \mathrm{SO}_{4}$ concentration was monitored by collecting spectra in the wavelength range of 300 to $800 \mathrm{~nm}$ with a scan speed of $2 \cdot 10^{2} \mathrm{~nm} \cdot \mathrm{s}^{-1}$ and using pure water as background.

\subsection{Size Exclusion Chromatography}

Size exclusion chromatography (SEC) was used to evaluate the purity and oligomerization state of $\gamma$-globulin in solution, and to purify the sample prior to the SAXS characterization of its major constituents. An analytical SD200 3.2/30 SEC column was used to separate $20 \mu \mathrm{L}$ of a $30 \mathrm{mg} / \mathrm{mL}$ sample using a flow rate of $50 \mu \mathrm{L} / \mathrm{min}$, collecting $50 \mu \mathrm{L}$ fractions and monitoring absorption at $280 \mathrm{~nm}$. An aqueous $150 \mathrm{mM} \mathrm{NaCl}$ solution was used both as eluent and as solvent for the $\gamma$-globulin sample. Separation was carried out at $8^{\circ} \mathrm{C}$. The composition of relevant fractions was checked by gel electrophoresis (SDS-PAGE). Three dilutions of representative fractions were heated $10 \mathrm{~min}$ at $95^{\circ} \mathrm{C}$ in a loading dye containing beta-mercaptoethanol, loaded on a $12 \%$ Acrylamide/bis-acrylamide denaturing gel at $40 \mathrm{~mA}$ for $90 \mathrm{~min}$. PageRuler Unstained Protein Ladder (Thermo Scientific) was used as molecular weight marker. The gel was stained with Instant Blue Coomassie stain (Expedeon). The relative mass amount corresponding to the elution peaks was evaluated by the integral of the chromatogram and verified by Gaussian peak fitting. Preparative SEC was performed at $4^{\circ} \mathrm{C}$ loading $5 \mathrm{~mL}$ of an approximately $100 \mathrm{mg} / \mathrm{mL}$ solution on a SD200 26/60 column and eluting at $3 \mathrm{~mL} / \mathrm{min}$ flow rate with a buffer containing $50 \mathrm{mM}$ HEPES $\mathrm{pH}=7.5$ and $150 \mathrm{mM} \mathrm{NaCl}$. Absorbance at $280 \mathrm{~nm}$ was monitored and $6 \mathrm{~mL}$ fractions were collected. Purified monomer and dimer solutions for SAXS were obtained by pooling three representative fractions from the monomer and dimer peak. The fractions were concentrated using $10 \mathrm{kDa}$ MWCO amicon centrifugal concentrators to about $32 \mathrm{mg} / \mathrm{mL}$. Concentrated solutions were used to prepare dilution series for SAXS characterization of $\gamma$-globulin monomer and dimer, employing the same buffer used for SEC.

\subsection{Small-angle X-ray Scattering}

SEC-purified $\gamma$-globulin monomer and dimer solutions were characterized by SAXS at the cSAXS beamline at the Swiss Light Source (Paul Scherrer Institut, Villigen, $\mathrm{CH}$ ) at room temperature. Samples were measured in $1 \mathrm{~mm}$ capillaries using an X-ray energy of $11.2 \mathrm{keV}(\lambda=1.11 \AA)$ with a sample-to-detector distance of $2 \mathrm{~m}$, resulting in a $q$ range of $0.005-0.5 \AA^{-1}$, with the scattering vector $q=4 \pi \sin \theta / \lambda$, where $2 \theta$ is the scattering angle. The scattered intensity was collected with a PILATUS $2 \mathrm{M}$ detector. 
In order to characterize protein-protein interactions in $\gamma$-globulin as a mixture, SAXS measurements were performed on solutions without prior purification at the ID02 beamline ${ }^{60}$ of the ESRF, (Grenoble, France). Two sets of samples, the first consisting in a broad concentration range $(5-200 \mathrm{mg} / \mathrm{mL})$ of $\gamma$-globulin in 20 mM HEPES buffer pH 7.0 with $150 \mathrm{mM} \mathrm{NaCl}$ and the second consisting in highly concentrated (93-309 $\mathrm{mg} / \mathrm{mL}$ ) $\gamma$-globulin in pure water, were measured using a flow capillary. An X-ray energy of $12.5 \mathrm{keV}$ was employed ( $\lambda=0.995 \AA$ ) using a sample-to-detector distance of $2 \mathrm{~m}$. The scattered intensity was collected with a $170 \mathrm{~mm}$ x $170 \mathrm{~mm}$ Rayonix MX-170HS CCD detector. The resulting $q$ range was $0.004 \AA^{-1}$ to $0.387 \AA^{-1}$.

Additional data from $\gamma$-globulin solutions in the presence of $\mathrm{NaCl}, \mathrm{Na}_{2} \mathrm{SO}_{4}$ and $\mathrm{NaSCN}$ were collected at station 6.2 of the Synchrotron Radiation Source (SRS) at the Daresbury Laboratory, (Warrington, UK). The beam energy was $8.8 \mathrm{keV}(\lambda=1.51 \AA)$. The scattered intensity was registered with a 200 mm-radius quadrant detector located $3.3 \mathrm{~m}$ from the sample. The accessible $q$ range was thus from $0.008 \AA^{-1}$ to $0.25 \AA^{-1}$. The detailed data correction and calibration has been described in a previous publication. ${ }^{11}$

\subsection{Small-angle neutron scattering}

Concentrated $\gamma$-globulin solutions in pure heavy water and semidilute $\gamma$-globulin solutions containing electrolytes $\left(\mathrm{NaCl}\right.$ and $\left.\mathrm{Na}_{2} \mathrm{SO}_{4}\right)$ near the critical salt concentration were characterized using SANS at two instruments, i.e. instrument D11 at the ILL (Grenoble, France) and instrument KWS-2 ${ }^{61}$ (Forschungszentrum Jülich) located at FRMII (Garching, Germany). Details of measurements performed with KWS2 and data analysis were described in a previous publication. ${ }^{62}$

Proteins and salts were dissolved in $\mathrm{D}_{2} \mathrm{O}$ and mixed or diluted to the desired concentration. Protein solutions were filled into quartz cells. Absolute scattering cross section was calibrated using $\mathrm{H}_{2} \mathrm{O}$ in a $1 \mathrm{~mm}$ quartz cell. For D11 (ILL) the wavelength of the neutrons was fixed at $6 \AA$ with $9 \% \Delta \lambda / \lambda$ and data from sample-to-detector distances of $1.5 \mathrm{~m}, 8 \mathrm{~m}$ and $20 \mathrm{~m}$ (corresponding collimation lengths $5.5 \mathrm{~m}, 8 \mathrm{~m}$ and $20.5 \mathrm{~m}$ ) were merged to yield an accessible $q$ range from 0.003 or $0.01 \AA^{-1}$ to $0.431 \AA^{-1}$. Samples were measured in $2 \mathrm{~mm}$ quartz cells and $\mathrm{H}_{2} \mathrm{O}$ in a $1 \mathrm{~mm}$ quartz cell has been used as a secondary calibration standard for absolute intensity calibration, cross-calibrated against H/D polymer blends. The differential scattering cross section for D11 at $6 \AA$ is $0.983 \mathrm{~cm}^{-1}$.

For KWS-2, the neutron beam has a wavelength of $4.5 \AA$. Two configurations of sample-to-detector distance of $2 \mathrm{~m}$ and $8 \mathrm{~m}$ allow measurements of the scattered intensity in a $q$ range between 0.008 and $0.30 \AA^{-1}$. Detector sensitivity corrections and transformation to absolute scattering cross section were made with a secondary Plexiglas standard.

\subsection{Data analysis}

The scattering intensity $I(q)$ for a polydisperse or non-spherical system, such as a protein solution, can be 
expressed as:

$$
I(q)=N_{p}(\Delta \rho)^{2} V_{P}^{2} P(q) \bar{S}(q)
$$

In this expression, $N_{P}$ is the number of protein molecules per unit volume in the solution, $V_{P}$ is the volume of a single protein and $\Delta \rho=\left(\rho_{P}-\rho_{S}\right)$, is the scattering contrast between the protein and the solvent. $P(q)$ is the form factor of a given protein. The effective structure factor $\bar{S}(q)$ is calculated based on the average structure factor approximation. ${ }^{63}$ However, effects such as protein conformational changes, flexibility and anisometry can complicate the interpretation of small-angle scattering data. ${ }^{22,23}$

In the present work, we aim for an understanding of the broad features of the protein-protein interactions in solutions of bovine $\gamma$-globulin. While bovine $\gamma$-globulin is a mixture of different variants of antibodies, its major constituents are IgG-type antibodies with similar molecular weights and overall shapes. This justifies the use of a single form factor in the description of the scattering intensity. We use the form factor of a monodisperse disk to model the IgGs of $\gamma$-globulin. A short and constant-range protein-protein interaction of variable strength is assumed and modeled as a square well (SW) pair potential, $U_{S W}(r)$ :

$$
\frac{U_{S W}(r)}{k_{B} T}=\begin{array}{r}
r<2 R \\
u_{S W}=\ln \left(\frac{12 \tau \Delta}{2 R+\Delta}\right)
\end{array} \quad \begin{array}{r}
2 R \leq r<2 R+\Delta \\
r>2 R+\Delta
\end{array}
$$

Here, $k_{B}$ is the Boltzmann constant, $T$ is the absolute temperature, $\Delta$ is the range of the interaction and $u_{S W}$ is the depth of the potential well. The parameter $\tau$ ("stickiness") is related to $u_{S W}$ by: 64

$$
\tau=\frac{1}{12 \varepsilon} e^{\frac{u_{S W}}{k_{b} T}}
$$

Here, $\varepsilon$ is the perturbation parameter, and is the relative range of the potential defined as $\Delta=\varepsilon /(2 R+\Delta)$.

To account for effects of non-sphericity, the effective radius $\mathrm{R}$ is chosen such that a hard sphere of this radius has the same second virial coefficient as the hard disk corresponding to the form factor.

The structure factor is then derived analytically using the perturbative solution of the Percus-Yevick closure relation as described by Menon ${ }^{64}$ and as implemented in the NCNR SANS analysis package of the IGOR pro suite. ${ }^{65}$ The assumption of an interaction potential with constant range (in the order of $10 \%$ of the effective sphere diameter) is included by keeping the perturbation parameter $\varepsilon=0.1$ during the fit. The volume fraction is calculated from the $\gamma$-globulin concentration using a specific volume of $0.739 \mathrm{~mL} / \mathrm{g} .{ }^{39} \mathrm{The}$ disk size is also kept constant. Three fit parameters are allowed to vary: a background term, the solvent scattering length 
density and the stickiness parameter $\tau$. The fitted value of $\tau$ is then used to calculate the potential well depth. The oligomeric state of bovine $\gamma$-globulin is not explicitly considered in the fit procedure.

\section{Results}

\subsection{Composition of $\gamma$-globulin and SAXS characterization of monomer and dimer}

The SEC elution profile of $\gamma$-globulin features two major peaks, as shown in Fig. 1a. A (reducing) SDS-PAGE was run on two chromatographic fractions representative of the peaks, each loaded onto the gel in triplicates with decreasing amounts of protein (Fig. 1b). Both fractions showed bands corresponding to the molecular weight of the heavy and light chains of IgG. The lower molecular weight SEC peak corresponds to the IgG monomer. The higher molecular weight SEC peak (ca. $40 \%$ of the protein mixture) can be attributed to idiotype anti-idiotype dimerization of $\gamma$-globulin mediated by the antigen binding fragments (Fab) of the IgG. This kind of dimerization is a characteristic of polyvalent antibodies obtained from pooled sera, ${ }^{66,67}$ which has been reported both in human and bovine ${ }^{68} \mathrm{IgG}$ mixtures and has been studied by electron microscopy ${ }^{68,69}$ and X-Ray crystallography. ${ }^{70}$ It has also been considered in a recent scattering study by Stingaciu et al. focusing on the internal dynamics of human IgGs. ${ }^{42}$ Idiotype anti-idiotype dimerization is understood as arising from a large number of different complementary idiotype anti-idiotype IgG pairs contained in the $\gamma$-globulin preparation. Such preparations are produced from pooled sera of multiple animals, each producing a limited repertoire of antigen binding regions in their population of antibodies. The pooling of the sera results in the increased probability that, by chance, a particular $\operatorname{IgG}$ is recognized by a complementary one and dimerizes. The dimers in the final product are therefore an ensemble of antibody pairs produced from a number of different equilibria. The relative abundance of dimers is known to increase with the number of starting sera, and storage conditions of the preparation also play a role.$^{67}$ This kind of dimerization has been also suggested to play a role in the therapeutic effect of IVIG in specific cases. ${ }^{71,72,73}$

In order to address the monomer and dimer shapes, SAXS measurements were performed on solutions at 1, 2, $10,15 \mathrm{mg} / \mathrm{mL}$ monomer and at $2,420,30 \mathrm{mg} / \mathrm{mL}$ dimer, so to evaluate the small-angle scattering from approximately the same molar amounts of monomeric and dimeric species. Comparing the buffer-subtracted SAXS profiles in the monomer and dimer concentration series, after normalization by protein mass concentration, no significant discrepancies at low $q$ are visible for any sample except for the $15 \mathrm{mg} / \mathrm{mL}$ monomer (Fig. S1 in the supporting information). This indicates that the contribution of the structure factor and the concentration-dependent shift of the dimerization equilibrium is indeed negligible for diluted monomer and dimer samples over short periods of time (up to a few days).

We assumed that the chromatographic step separates sufficiently stable monomers and dimers, so that subsequent dimer formation in the monomer solution and dissociation in the dimer solution are negligible. 
Dimer dissociation has indeed been reported, for an analogous human-derived product, to occur over long times. ${ }^{66,74,75}$ From the overall parameters extracted from SAXS measurements (see below), this assumption is justified.

Fig. 2a shows a double logarithmic plot of two representative buffer-subtracted SAXS profiles for monomer and dimer at 1 and $4 \mathrm{mg} / \mathrm{mL}$, respectively. The monomer form factor fit (Fig. 2a) was evaluated with CRYSOL,${ }^{76}$ using the crystal structure of human IgG1 b12 antibody (1HZH.pdb). ${ }^{77}$ The good fit may reflect the similarity between the crystal structure used and the most populated conformation of the major subclass of bovine serum $\mathrm{IgG}$, bovine $\operatorname{IgG} 1{ }^{78}$ This crystal structure is the best fitting of the three complete $\operatorname{IgG}$ crystal structures available on the Protein Data Bank (see Fig. S2).
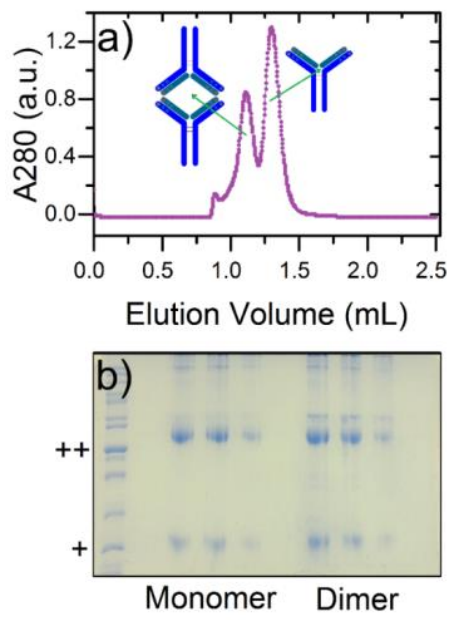

Figure 1 a) Size Exclusion Chromatography elution profile of $\gamma$-globulin, with sketches of the IgG monomer and idiotype anti-idiotype dimer. b): SDS-PAGE of monomer (three lanes on the left) and dimer (three lanes on the right) fractions, in three dilutions each. The symbol + indicates the $20 \mathrm{~kg} / \mathrm{mol}$ molecular weight marker, ++ indicates the 50 $\mathrm{kg} / \mathrm{mol}$ marker.

Overall parameters for monomer and dimer in solution are shown in Table 1, calculated from scattering curves extrapolated at infinite dilution using PRIMUS. ${ }^{79}$ Molecular weights extracted from the Porod volume $V_{\text {Porod }}$ are consistent with the expected values for IgG monomers and dimers, while $D_{\max }$ and $R_{g}$ monomer values are close to the ones reported in literature ${ }^{80,43,81}$ for monoclonal antibodies of human and non-human origin. It must be stressed that in our case scattering profiles originate from a relatively heterogeneous population, and 
the overall parameters must be considered as reflecting a weighted average from this population.

\begin{tabular}{|l|c|c|c|c|}
\hline & $\begin{array}{c}\mathrm{R}_{\mathrm{g}} \\
(\AA)\end{array}$ & $\begin{array}{c}\mathrm{D}_{\max } \\
(\AA ̊)\end{array}$ & $\begin{array}{c}\mathrm{V}_{\text {Porod }} \\
\left(\AA^{3}\right)\end{array}$ & $\begin{array}{c}\mathrm{MW} \\
(\mathrm{kDa})\end{array}$ \\
\hline Monomer & $52.6 \pm 3.7$ & 184 & 238325 & 149 \\
\hline Dimer & $76.1 \pm 1.7$ & 223 & 621987 & 389 \\
\hline
\end{tabular}

Table 1 Radius of gyration $\left(\mathrm{R}_{\mathrm{g}}\right)$ was estimated with AUTORG. ${ }^{82}$ Maximum intramolecular distance $\left(\mathrm{D}_{\max }\right)$ was estimated with DATGNOM. ${ }^{82}$ Porod Volume ( $V_{\text {Porod }}$ ) was estimated with DATPOROD. ${ }^{82} \mathrm{~V}_{\text {Porod }}$ was converted to MW multiplying Vp by $0.625 \mathrm{Da} \cdot \AA^{-383}$

Typical pair distance distribution functions $P(r)$, calculated with $\mathrm{GNOM}^{84}$ and using $D_{\max }$ and $R_{g}$ values evaluated as described above, are shown for monomer and dimer in Fig. 2b. Similar $P(r)$ have been reported for monoclonal antibodies $43,81,85,86,87$. The shape of the $P(r)$, asymmetric and featuring a broadened or even twinned peak, is likely to arise from the coarse grained details of the branched antibody structure. The same shape can in fact also be seen in $P(r)$ calculated from X-ray crystal structures ${ }^{87}$. However, the features of the $P(r)$ have also been interpreted as reflecting the conformational heterogeneity of antibodies in solution ${ }^{43,81}$.

In order to model the structure of the dimer, an $a b$ initio bead modeling approach employing DAMMIF ${ }^{88}$ was used. We assumed that the dimeric IgA content in the purified dimer contributes to the scattering as a minor impurity. $P(r)$ was calculated with GNOM for the scattering profile of a $4 \mathrm{mg} / \mathrm{mL}$ dimer sample up to a maximum $q$ of $0.176 \AA^{-1}$, and used to repeat 30 DAMMIF runs. The $D_{\max }$ used (233 $\mathrm{A}$ ) was estimated with DATGNOM $^{82}$ from the scattering profile. $\mathrm{D}_{2}$ point group symmetry and prolate anisometry are expected for a Fab-mediated IgG dimer, and were specified for the bead modeling. The resulting output was further processed with DAMAVER, ${ }^{89}$ yielding an averaged and a filtered model (total spread region and most populated volume, superimposed in Fig. 2b, inset). The averaged Normalized Spatial Discrepancy (NSD) of the thirty resulting models is $0.683 \_ \pm 0.242$. Three models were rejected as outliers before averaging. Strikingly the model features the ring-like structure reported for human idiotype anti-idiotype IgG dimers in earlier electron microscopy studies, ${ }^{68}$ also featuring dimers of sizes in the $20-30 \mathrm{~nm}$ range.

This model may be regarded as the first solution structure of an average idiotype anti-idiotype dimer. It must be stressed, however, that the model is idealized due to the symmetry constraints and it reflects the form factor arising from a supposedly rather heterogeneous population of dimers. Therefore we abstain from speculations on the predominant geometry (open hinge or closed hinge $\mathrm{A}_{\mathbf{4}}^{75}$ ) for the dimer. The possible residual content in dimeric IgA, which has a distinctly different "tail-to-tail" geometry, seems not to contribute significantly to the scattering profile.

The monomer and dimer fractions present in bovine $\gamma$-globulin comprise different monoclonal antibodies and 
idiotype anti-idiotype pairs. Nevertheless it was possible to relate the monomer and dimer scattering curves to structural models, as these different constituents share similar shape, size and molecular weight.

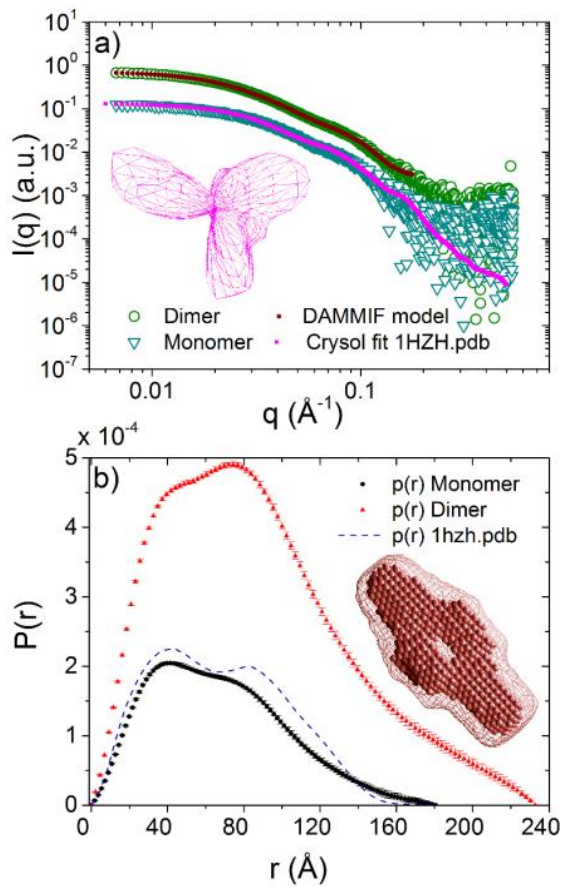

Figure 2 a) SAXS profiles and model fitting for monomer $(1 \mathrm{mg} / \mathrm{mL})$ and $\operatorname{dimer}(4 \mathrm{mg} / \mathrm{mL})$. The monomer scattering curve is fitted using CRYSOL and the crystal structure 1hzh.pdb. The dimer data are fitted by the profile of a representative DAMMIF ab initio model. Inset: monomer envelope visualized as mesh with MASSHA $^{90} \mathrm{~b}$ ) Pair distance distribution functions, $P(r)$ for monomer and dimer. Inset: dimer model, with total spread region (mesh) and most populated volume (beads) visualized and superimposed with UCSF Chimera. ${ }^{91}$ The $P(r)$ calculated from the monomer crystal structure and scaled to the data is also shown as dashed line.

\subsection{Effective interactions in $\gamma$-globulin solutions characterized by SAXS and SANS}

In this section, we address the effective interactions in $\gamma$-globulin solutions as a function of protein concentration employing SAXS and SANS. The scattering profiles shown here are collected from $\gamma$-globulin dissolved "as received", without prior purification i.e. containing all monomeric and dimeric species. Samples in a broad range of $\gamma$-globulin concentrations were studied, both at moderate ionic strengths and at low ionic strengths for higher protein concentrations. A simplified model with a single disk form factor is used to extract the effective protein-protein interactions. 
The size of the disk used to calculate the form factor was optimized on the scattering profiles of dilute $\gamma$-globulin in a preliminary fitting step. Fig. 3 shows that the disk form factor reasonably describes the high- $q$ portion of the data. A comparison with the CRYSOL fit with the $1 \mathrm{hzh}$ crystal structure is also shown. The disk used to fit the SAXS data has a radius of $70 \AA$ and a length of $15 \AA$, while the one used to fit the SANS data has a radius of $60 \AA$ and a length of $12 \AA$. The diameters of the equivalent spheres with the same second virial coefficient as the disks are $105 \AA$ for SAXS and $89 \AA$ for SANS respectively. The disks are shown in the inset in Fig. $3 \mathrm{~b}$ superimposed with the crystal structure. If additional short range attractive interactions are considered (Disk+SW in Fig. 3) the fit considerably improves at low $q$ even for these dilute samples.

In Fig. 4 we show concentration-normalized SAXS profiles of a series of $\gamma$-globulin solutions in buffer (4a) and in pure water (4b). While there is substantial superposition of the profiles at high $q$, there is a clear trend of decreased intensity in the low $q$ region. This indicates a reduction in the protein-protein attractive interactions which we ascribe to the repulsive contribution of excluded volume effects. The same trend is visible for even higher concentrations in SANS profiles of $\gamma$-globulin in pure $\mathrm{D}_{2} \mathrm{O}$ (Fig. 4c). To quantify this trend, the disk form factor was used to extract the effective structure factors from the scattering curves.

SAXS data from $\gamma$-globulin in buffer up to $200 \mathrm{mg} / \mathrm{mL}$ are well described by the model (solid lines in Fig. 4) . For samples with higher concentrations, while the overall fit is reasonable, in particular in the low $q$ region, an additional correlation peak becomes visible in the fit curves at $q \sim 0.08 \AA^{-1}$, which is due to the correlation between the disk-like particles (red arrows in Fig. 4b, 4c). This mismatch indicates that a hard-particle form factor cannot fully describe the behavior of concentrated flexible proteins. Conformation change due to the flexibility of the IgG may smear the protein-protein correlations. Details of fitting parameters are reported in the supporting information (Table S1). 


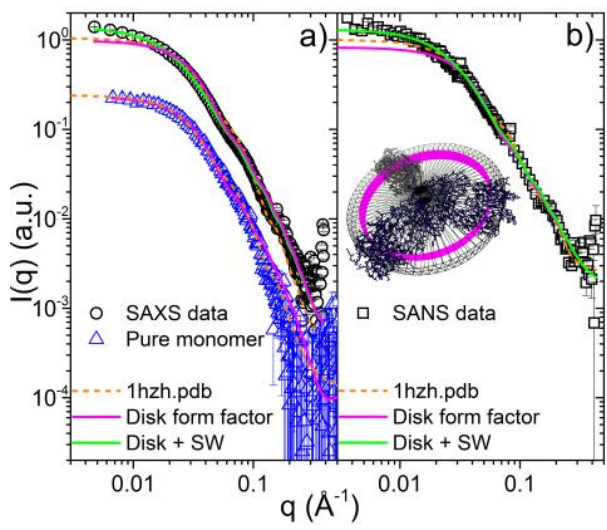

Figure 3 a) SAXS profiles of the SEC-purified monomer ("pure monomer") at $2 \mathrm{mg} / \mathrm{mL}$, and of the original $\gamma$ globulin at $5 \mathrm{mg} / \mathrm{mL}$, in the respective buffers. Superimposed are the CRYSOL fit with $1 \mathrm{hzh} . \mathrm{pdb}$ and an appropriate background (dashed orange line), the fit with a disk form factor alone (magenta solid line) and the fit with both the disk form factor and a square well (SW) structure factor (green solid line).b) SANS profile of $\gamma$-globulin $5 \mathrm{mg} / \mathrm{mL}$ in $\mathrm{D}_{2} \mathrm{O}$ with $200 \mathrm{mM} \mathrm{NaCl}$. Superimposed are the $\mathrm{CRYSON}^{92}$ fit with 1 hzh.pdb assuming 90\% H/D exchange and an appropriate background (dashed orange line), the fit with a disk form factor alone (magenta solid line) and the fit with both the disk form factor and the SW structure factor (green solid line). The inset shows the disks in comparison with the 1hzh crystal structure. The disk used for subsequent SAXS fits is shown as mesh, the inner magenta ring delimits the disk used for subsequent SANS fits (image produced with UCSF Chimera ${ }^{91}$ ). The profiles in a) and b) were vertically shifted and only every third data point is shown for clarity.

Fig. 5a shows the square well structure factors obtained from data fitting. For low protein concentrations, the structure factor shows a strong low $q$ upturn, indicating the presence of non-negligible attractive interactions. At higher protein concentrations, the values of $\bar{S}(q)$ at low $q$ decrease and eventually fall below one. Fig. $5 \mathrm{~b}$ shows the depth of the square well interaction potential as a function of protein volume fraction. The overall trend is a reduction of the depth of the potential well for increasing protein concentration. Comparing $\gamma$-globulin in $\mathrm{H}_{2} \mathrm{O}$ and $\mathrm{D}_{2} \mathrm{O}$ with $\gamma$-globulin in buffer, the strength of interaction appears to be reduced when increasing ionic strength.

Given that our modeling strategy neglects dimerization, the effective potential should not be over-interpreted. The corresponding value of $\tau$ should not be taken as predictive of phase separation, for a given volume fraction. 
Shift in the dimerization equilibria towards dimer formation might interfere with the structure factor for the concentrated solutions. However, the reduction of the attractive interaction due to steric exclusion is indeed likely to exist for the most concentrated samples regardless of the exact weighted contribution of monomer and dimer to the form factor. A similar effect has been also observed in other studies on self-crowded proteins..$^{93} \mathrm{We}$ interpret this as a sign that the structure of concentrated protein solutions is more and more influenced by excluded-volume effects due to the closer packing rather than by the attractive features of the potential. However, we cannot exclude a screening contribution by the ions released from the $\gamma$-globulin lyophile.

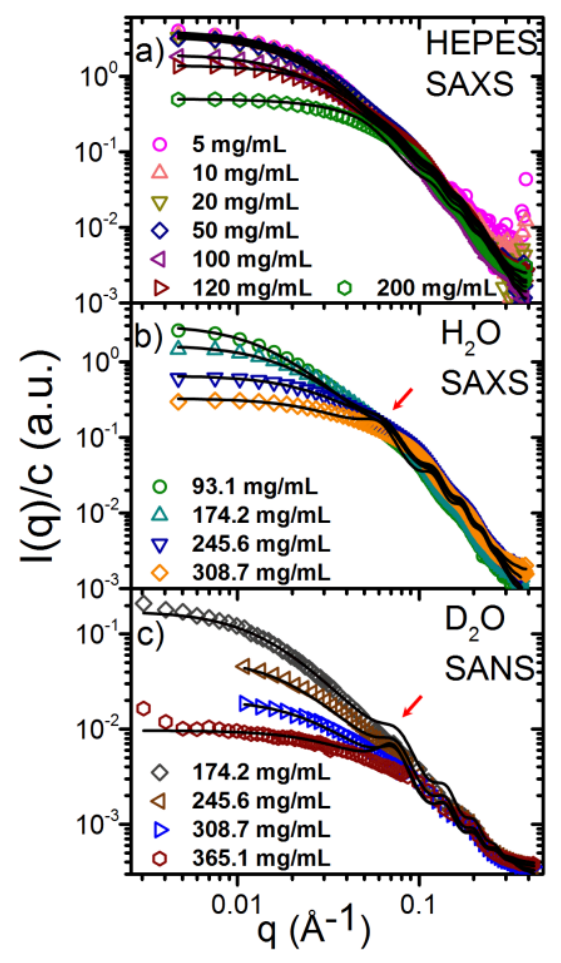

Figure 4 Concentration-normalized scattering profiles for $\gamma$-globulin without prior purification. For all scattering profiles, one point in five is shown for clarity. a) SAXS profiles for a concentration series in $20 \mathrm{mM}$ HEPES $\mathrm{pH}=7.0150 \mathrm{mM} \mathrm{NaCl}$ b) SAXS profiles for a concentration series of in $\mathrm{H}_{2} \mathrm{O}$ c) SANS profiles for a concentration series in $\mathrm{D}_{2} \mathrm{O}$. The curves fitted to the scattering profiles are shown as solid lines. The arrows mark the correlation peak 

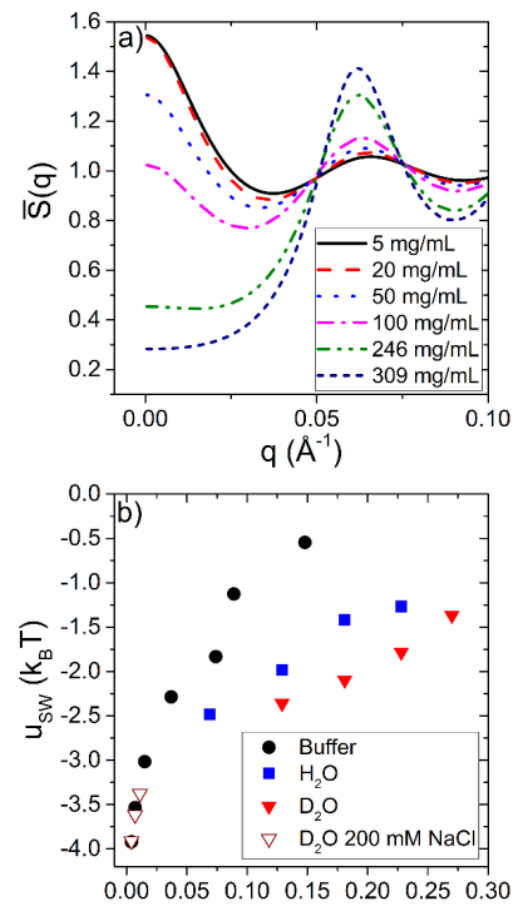

$\Phi$

Figure 5 a) Structure factors calculated from the fit parameters for $\gamma$-globulin in buffer and pure water. The complete set of structure factors from the SAXS data in buffer, light and heavy water are shown in Fig. S3. b) Square well potential depth as a function of volume fraction $\Phi$, calculated from the known sample concentration using as specific volume ${ }^{39}$ $0.739 \mathrm{~mL} / \mathrm{g}$. SANS profiles at low concentration in $\mathrm{D}_{2} \mathrm{O}$ in the presence of $200 \mathrm{mM} \mathrm{NaCl}$ (open symbols in Fig. 5 b) are shown in Fig. S4.

\subsection{Stability of $\gamma$-globulin solutions as a function of ionic strength and salt type}

In this section, the stability of $\gamma$-globulin solutions, used without prior purification and in the presence of salts as cosolutes, is addressed in dependence of salt concentration and type.

Turbidity of $\gamma$-globulin solutions can be monitored by the apparent light absorption in the wavelength range 500 to $800 \mathrm{~nm}$. In turbid solutions, suspended precipitate scatters visible light and gives an apparent increase of absorbance, which is denoted as attenuance, $D .{ }^{94}$ This quantity is defined in an analogus way as an 
absorbance, as the logarithm of the ratio of incoming to transmitted radiant power at a given wavelength. Typical UV-vis attenuance spectra for $\gamma$-globulin solutions with increasing $\mathrm{Na}_{2} \mathrm{SO}_{4}$ and $\mathrm{NaCl}$ concentrations are shown in Fig. 6a and Fig. S5, respectively.

The stability of the protein solutions is better appreciated plotting the attenuance at $600 \mathrm{~nm}$ as a function of salt concentration (Fig. 6b-d). Attenuance values larger than 0.1 correspond to visibly turbid, phase-separated solutions. With both salts two transitions upon increasing concentration are recognizable. The first one, from a turbid protein solution to a clear solution; taking place at a salt concentration $c_{1}\left(25 \mathrm{mM}\right.$ for $\mathrm{Na}_{2} \mathrm{SO}_{4}$ and 20 $\mathrm{mM}$ for $\mathrm{NaCl})$. The second, from a clear to a turbid solution, taking place at a salt concentration $c_{2}(0.5-0.7$ $\mathrm{M}$ for $\mathrm{Na}_{2} \mathrm{SO}_{4}$ and $3.2 \mathrm{M}$ for $\mathrm{NaCl}$ ). An increase in $\gamma$-globulin concentration up to $50 \mathrm{mg} / \mathrm{mL}$ does not change $c_{1}$ significantly. Conversely, $c_{2}$ occurs at lower salt concentration when the protein concentration is increased. In presence of $\mathrm{NaSCN}$, up to $4 \mathrm{M}$, protein solutions are stable in all the high-salt conditions, and no second transition is observed (data not shown). This is consistent with the salting-in nature of the thiocyanate anion, known to adsorb on hydrophobic moieties of proteins, including monoclonal antibodies..$^{95}$

To further explore the nature of $c_{1}$, the precipitate present at low salt concentration $\left(<c_{1}\right)$ was pelleted by centrifugation $\left(10 \mathrm{~min}\right.$ at $6990 \mathrm{~g}$ at $23^{\circ} \mathrm{C}$ ) and the residual $\gamma$-globulin concentration in the supernatant was determined by UV absorption at $280 \mathrm{~nm}$. It is found that most of the protein is still in solution (around $92 \%$ $\mathrm{w} / \mathrm{w}$ for a $36 \mathrm{mg} / \mathrm{mL}$ dispersion of $\gamma$-globulin in pure $\mathrm{H}_{2} \mathrm{O}$ ). The redispersed precipitate shows a much narrower interval of ionic strengths which allows for a clear solution (Fig. 6d). 

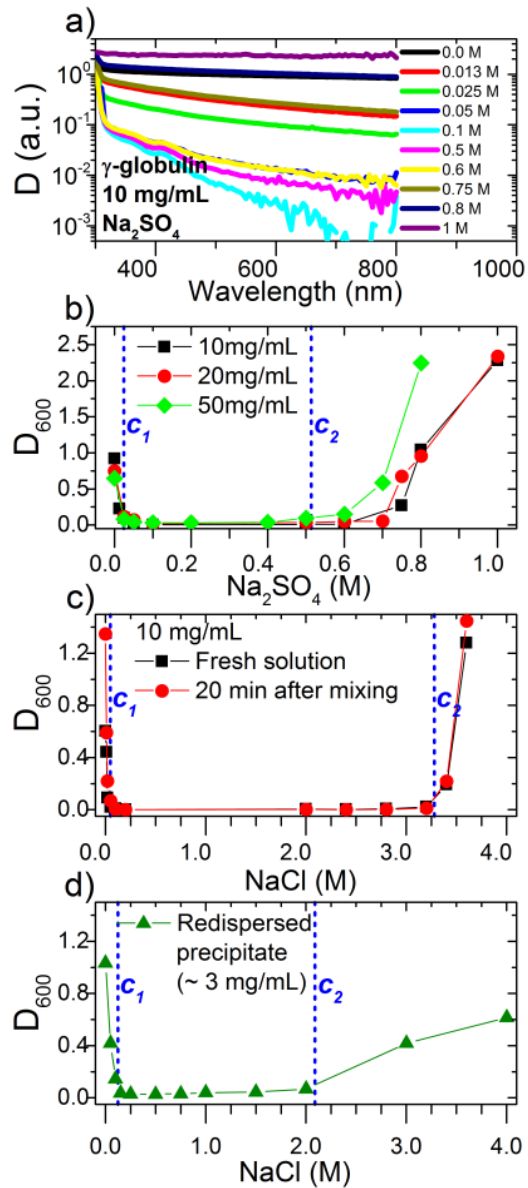

Figure 6 Stability of $\gamma$-globulin solutions by attenuance $(D)$ measurements. a) Attenuance of $10 \mathrm{mg} / \mathrm{mL} \gamma$-globulin solutions for increasing $\mathrm{Na}_{2} \mathrm{SO}_{4}$ concentration in the range $300-800 \mathrm{~nm}$. b) Plots of attenuance at $600 \mathrm{~nm}$ for 10, 20 and $50 \mathrm{mg} / \mathrm{mL} \gamma$-globulin solutions with increasing $\mathrm{Na}_{2} \mathrm{SO}_{4}$ concentration. c) Plots of attenuance at $600 \mathrm{~nm}$ for $10 \mathrm{mg} / \mathrm{mL}$ solution with increasing $\mathrm{NaCl}$ concentration. Data for sample immediately after preparation and 20 minutes after preparation are shown. d) Plot of attenuance at $600 \mathrm{~nm}$ of low ionic strength insoluble fractions obtained from $36 \mathrm{mg} / \mathrm{mL}$ dispersions of $\gamma$-globulin in pure water, pelleted by centrifugation and resuspendend in $\mathrm{NaCl}$ aqueous solutions in the range 0-4M, showing a narrower window of ionic strength compatible with stable, clear solutions. In (b) to (d) samples with salt concentrations below $c_{1}$ and above $c_{2}$ are visibly turbid.

Therefore the first transition must be due to a relatively small subpopulation of the monoclonal components of $\gamma$-globulin. In fact, different monoclonal IgG antibodies have been described as soluble or non-soluble at low ionic strength ${ }^{96}$. The non-soluble ones feature, at a given $\mathrm{pH}$, electrostatic potential surfaces with large compatible areas of opposite sign. An analogous charge anisotropy driven aggregation has been studied also 
in $\beta$-lactoglobulin ${ }^{97}$ and found to affect viscosity in another monoclonal antibody ${ }^{98}$. This kind of charge interaction favors self-association of the antibodies unless the charge is screened by a sufficiently high ionic strength. In bovine $\gamma$-globulin we suppose that the vast majority of monoclonal antibodies does not belong to this low-ionic-strength-non-soluble category, but a subpopulation with this characteristic is responsible for the observed first transition. In such a polyclonal mixture as $\gamma$-globulin, turbidity could also arise from attraction between different monoclonal antibodies in which the surface charges or charge patterns are complementary. This subpopulation of antibodies with strong attractive interactions due to complementary charge patterns, is also consistent with the higher $c_{1}$ and lower $c_{2}$ for the redispersed precipitates.

We note that $\gamma$-globulin, albeit insoluble in the absence of salt at lower protein concentrations, results in clear, viscous solutions in pure water above $70 \mathrm{mg} / \mathrm{mL}$. Clear solutions are then obtained in the presence of a low concentration of salt or with a sufficient concentration of the antibodies. The solubilization of the poorly soluble subpopulation at high protein concentration might then also result from screening by other antibodies, enhanced release of counter-ions or as a side-effect of self-buffering.

The solubilization of $\gamma$-globulin across the first transition $\left(c_{1}\right)$ is clearly seen in the SAXS scattering profiles for increasing salt concentrations and constant protein concentration shown in Fig. 7a,b and Fig. S6. A reduction of low $q$ intensity with increasing salt concentration is observed for all three salts, indicating an overall reduction of the attractive interactions. Those interactions are screened at higher ionic strength and stable, clear solutions are obtained.

Fitting the scattering profiles of $\gamma$-globulin solutions at low ionic strength using the model presented in the previous section allowed the extraction of an effective attractive protein-protein interaction potential (Fig. 7c). The overall attraction is reduced for increasing ionic strength. The effect of the three salts considered in this work appears comparable, with a slightly higher efficiency of $\mathrm{NaSCN}$ in reducing the protein-protein attraction.

As $c_{2}$ is approached, salting-out effects cause an increase of the low- $q$ intensity in SANS profiles. This behavior qualitatively suggests an increase of attractive interactions (Fig. S7). It was not possible to obtain a satisfactory fit of the scattering intensity using the disk and square well model to quantify the effect of the salts, possibly due to effects related to the high salt concentration. 

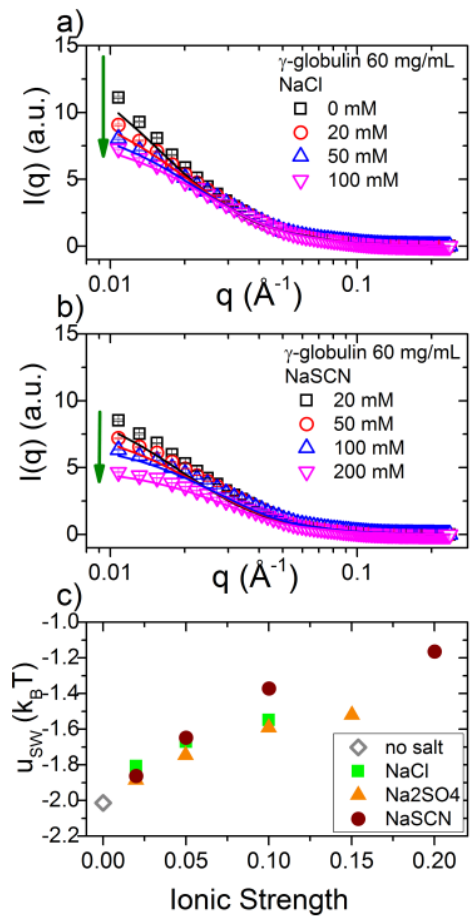

Figure $7 \mathrm{SAXS}$ profiles of $\gamma$-globulin at $60 \mathrm{mg} / \mathrm{mL}$ showing its solubilization by a) $\mathrm{NaCl}$ b) $\mathrm{NaSCN}$ at low ionic strengths. The solid lines are the fit to the data using the disk form factor with the square well interaction. The profiles for $\mathrm{Na}_{2} \mathrm{SO}_{4}$ and the fit are shown in Fig. S6. c) effect of the ionic strength of the three salts on the depth of the SW potential well.

\section{Conclusions}

The results discussed above lead to the following conclusions. Bovine $\gamma$-globulin is essentially a mixture of IgG monomers and idiotype anti-idiotype dimers. The dimers represent at least about $40 \%$ in mass of the proteins. The apparent discrepancy with previous QENS studies of the short time diffusion of $\gamma$-globulin being consistent with monomer diffusion might arise from the dynamics on short time scales in the crowded solution, with a possible role played by IgG flexibility.

SAXS and SANS profiles of $\gamma$-globulin can be described well by a square well structure factor and a disk form factor. This simple model indicates that the attractive interactions are dominant in protein solutions, but the strength is reduced with increasing concentration and adding buffer or salts.

The stability of bovine $\gamma$-globulin solutions depends on protein concentration and solution ionic strength. For 
solutions below $50 \mathrm{mg} / \mathrm{mL}$, two transitions are observed with increasing ionic strength. Below $c_{1}$ and above $c_{2}\left(c_{1}<c_{2}\right)$, solutions are visibly turbid. Protein aggregation below $c_{1}$ is most likely due to subpopulations of IgG molecules with attractive patches of complementary surface charge. These molecules are unable to dissolve in water in significant amounts unless the ionic strength is high enough to screen this charge interaction. A second transition is observed at high ionic strength which causes the precipitation of the proteins with a dependence on the salting-out character of the salt used. Concentrated protein solutions $(>70 \mathrm{mg} / \mathrm{mL})$ are clear even at lower ionic strengths. This is possibly due to the low-ionic strength soluble antibodies interacting with those which require salt for solubility, either directly or through release of associated ions.

The recent findings by Godfrin et al. ${ }^{99}$ on solutions of a monoclonal $\mathrm{IgG}$ in the presence of $\mathrm{Na}_{2} \mathrm{SO}_{4}$ stress the role of microstructure and dynamics for the rheological properties of antibody formulations. The investigated IgG1 was found to form clusters of dimers based on a combination of SANS, dynamic light scattering and neutron spin echo. Although the kind of dimerization found in $\gamma$-globulin is qualitatively different, as it derives from chemically specific Fab-Fab interactions, it could possibly play a role in dynamic clustering in concentrated $\gamma$-globulin solutions.

Further dynamics studies are desirable to address the intermediate time self-diffusion and the long time collective diffusion behavior of $\gamma$-globulin solutions. Dynamic light scattering and neutron spectroscopy (in particular neutron spin echo spectroscopy) would be the techniques of choice.

\section{Acknowledgements}

We gratefully acknowledge financial support from the DFG. We thank Dr. Christoph Schall (IFIB Tübingen) for assistance with analytical Size Exclusion Chromatography and Dr. Jun Han for collecting data at the cSAXS beamline of the PSI. We thank the ESRF for allocation of beamtime on ID2 and Richard A. Martin (School of Physical Sciences, University of Kent, Canterbury, United Kingdom), Christopher M. Martin, Graham F. Clark at SRS, Daresbury, Warrington, United Kingdom for their help with beamtime. Part of this work is based upon experiments performed at the KWS-2 instrument ${ }^{61}$ operated by JCNS at the Heinz MaierLeibnitz Zentrum (MLZ), Garching, Germany. We would like to thank Marco Grimaldo for fruitful discussions, and Sylvain Prévost for the helpful assistance.

\section{Supporting Information}

Additional SAXS and SANS data and fits for the $\gamma$-globulin solutions, the table of fit parameters and plots of the calculated structure factors. UV-vis attenuance measurements are also shown.

\section{Author Information}

Corresponding Author

Dr. Fajun Zhang 
* Email address: fajun.zhang@uni-tuebingen.de

Present Addresses

${ }^{\ddagger}$ Lunds Universitet, Physical Chemistry, Box 124, Lund 221 00, Sweden (F.R.-R.)

$\S$ ISIS, Rutherford Appleton Laboratory, Chilton, Didcot OX110QX, United Kingdom (M.W.A.S.)

\section{References}

1. Baumgartner, K.; Galm, L.; Nötzold, J.; Sigloch, H.; Morgenstern, J.; Schleining, K.; Suhm, S.; Oelmeier, S. A.; Hubbuch, J., Determination of protein phase diagrams by microbatch experiments: Exploring the influence of precipitants and $\mathrm{pH}$. International Journal of Pharmaceutics 2015, 479 (1), 28-40.

2. Raut, A. S.; Kalonia, D. S., Pharmaceutical Perspective on Opalescence and Liquid-Liquid Phase Separation in Protein Solutions. Molecular Pharmaceutics 2016, 13 (5), 1431-1444.

3. Bergfors, T. M., Protein Crystallization. Internat'l University Line: 2009.

4. Blakeley, M., Neutron macromolecular crystallography. Crystallography Reviews 2009, 15 (3), 157-218.

5. Chiti, F.; Dobson, C. M., Protein misfolding, functional amyloid, and human disease. Annual Review of Biochemistry 2006, 75, 333-366.

6. Galkin, O.; Vekilov, P. G., Mechanisms of homogeneous nucleation of polymers of sickle cell anemia hemoglobin in deoxy state. Journal of Molecular Biology 2004, 336 (1), 43-59.

7. Shiryayev, A.; Li, X.; Gunton, J. D., Simple model of sickle hemogloblin. The Journal of Chemical Physics 2006, 125 (2), 024902 .

8. Vekilov, P. G., Sickle - cell haemoglobin polymerization: is it the primary pathogenic event of sickle - cell anaemia? British Journal of Haematology 2007, 139 (2), 173-184.

9. Wang, Y.; Lomakin, A.; Hideshima, T.; Laubach, J. P.; Ogun, O.; Richardson, P. G.; Munshi, N. C.; Anderson, K. C.; Benedek, G. B., Pathological crystallization of human immunoglobulins. Proceedings of the National Academy of Sciences 2012, 109 (33), 13359-13361.

10. Pande, A.; Pande, J.; Asherie, N.; Lomakin, A.; Ogun, O.; King, J.; Benedek, G. B., Crystal cataracts: human genetic cataract caused by protein crystallization. Proceedings of the National Academy of Sciences 2001, 98 (11), 6116-6120.

11. Zhang, F.; Skoda, M. W.; Jacobs, R. M.; Martin, R. A.; Martin, C. M.; Schreiber, F., Protein interactions studied by SAXS: effect of ionic strength and protein concentration for BSA in aqueous solutions. The Journal of Physical Chemistry B 2007, 111 (1), 251-259.

12. Vivares, D.; Belloni, L.; Tardieu, A.; Bonnete, F., Catching the PEG-induced attractive interaction between proteins. The European Physical Journal E: Soft Matter and Biological Physics 2002, 9 (1), 15-25.

13. Liu, Y.; Fratini, E.; Baglioni, P.; Chen, W.-R.; Chen, S.-H., Effective long-range attraction between protein molecules in solutions studied by small angle neutron scattering. Physical Review Letters 2005, 95 (11), 118102.

14. Tardieu, A.; Le Verge, A.; Malfois, M.; Bonneté, F.; Finet, S.; Ries-Kautt, M.; Belloni, L., Proteins in solution: from x-ray scattering intensities to interaction potentials. Journal of Crystal Growth 1999, 196 (2), 193-203.

15. Tardieu, A.; Bonneté, F.; Finet, S.; Vivarés, D., Understanding salt or PEG induced attractive interactions to crystallize biological macromolecules. Acta Crystallographica 2002, D58, 1549-1553.

16. Wolf, M.; Roosen-Runge, F.; Zhang, F.; Roth, R.; Skoda, M. W.; Jacobs, R. M.; Sztucki, M.; Schreiber, F., Effective interactions in protein-salt solutions approaching liquid-liquid phase separation. Journal of Molecular Liquids 2014, 200, $20-27$.

17. Zhang, F.; Roth, R.; Wolf, M.; Roosen-Runge, F.; Skoda, M. W.; Jacobs, R. M.; Stzucki, M.; Schreiber, F., Charge-controlled metastable liquid-liquid phase separation in protein solutions as a universal pathway towards crystallization. Soft Matter 2012, 8 


\section{(5), 1313-1316.}

18. Platten, F.; Valadez-Pérez, N. E.; Castañeda-Priego, R.; Egelhaaf, S. U., Extended law of corresponding states for protein solutions. The Journal of Chemical Physics 2015, 142 (17), 174905.

19. Chen, S.-H.; Broccio, M.; Liu, Y.; Fratini, E.; Baglioni, P., The two-Yukawa model and its applications: the cases of charged proteins and copolymer micellar solutions. Journal of Applied Crystallography 2007, 40 (s1), s321-s326.

20. Yearley, E. J.; Zarraga, I. E.; Shire, S. J.; Scherer, T. M.; Gokarn, Y.; Wagner, N. J.; Liu, Y., Small-angle neutron scattering characterization of monoclonal antibody conformations and interactions at high concentrations. Biophysical Journal 2013, 105 (3), 720-731.

21. Grouazel, S.; Bonnete, F.; Astier, J.-P.; Ferte, N.; Perez, J.; Veesler, S., Exploring bovine pancreatic trypsin inhibitor phase transitions. The Journal of Physical Chemistry B 2006, 110 (39), 19664-19670.

22. Sarangapani, P. S.; Hudson, S. D.; Jones, R. L.; Douglas, J. F.; Pathak, J. A., Critical examination of the colloidal particle model of globular proteins. Biophysical Journal 2015, 108 (3), 724-737.

23. Castellanos, M. M.; Clark, N. J.; Watson, M. C.; Krueger, S.; McAuley, A.; Curtis, J. E., Role of Molecular Flexibility and Colloidal Descriptions of Proteins in Crowded Environments from Small-Angle Scattering. The Journal of Physical Chemistry B 2016, 120 (49), 12511-12518.

24. Weiner, L. M.; Surana, R.; Wang, S., Monoclonal antibodies: versatile platforms for cancer immunotherapy. Nature Reviews Immunology 2010, 10 (5), 317-327.

25. Waldmann, T. A., Immunotherapy: past, present and future. Nature Medicine 2003, 9 (3), 269-277.

26. Wang, Y.; Lomakin, A.; Latypov, R. F.; Laubach, J. P.; Hideshima, T.; Richardson, P. G.; Munshi, N. C.; Anderson, K. C.; Benedek, G. B., Phase transitions in human IgG solutions. The Journal of Chemical Physics 2013, 139 (12), 121904.

27. Wang, Y.; Latypov, R. F.; Lomakin, A.; Meyer, J. A.; Kerwin, B. A.; Vunnum, S.; Benedek, G. B., Quantitative Evaluation of Colloidal Stability of Antibody Solutions using PEG-Induced Liquid-Liquid Phase Separation. Molecular Pharmaceutics 2014, 11 (5), 1391-1402.

28. Ahamed, T.; Esteban, B. N.; Ottens, M.; Van Dedem, G. W.; Van der Wielen, L. A.; Bisschops, M. A.; Lee, A.; Pham, C.; Thömmes, J., Phase behavior of an intact monoclonal antibody. Biophysical Journal 2007, 93 (2), 610-619.

29. Lewus, R. A.; Darcy, P. A.; Lenhoff, A. M.; Sandler, S. I., Interactions and phase behavior of a monoclonal antibody. Biotechnology Progress 2011, 27 (1), 280-289.

30. Lewus, R. A.; Levy, N. E.; Lenhoff, A. M.; Sandler, S. I., A comparative study of monoclonal antibodies. 1. phase behavior and protein-protein interactions. Biotechnology Progress 2015, 31 (1), 268-276.

31. Rakel, N.; Bauer, K. C.; Galm, L.; Hubbuch, J., From osmotic second virial coefficient (B22) to phase behavior of a monoclonal antibody. Biotechnology Progress 2015, 31 (2), 438-451.

32. Rakel, N.; Baum, M.; Hubbuch, J., Moving through three - dimensional phase diagrams of monoclonal antibodies. Biotechnology Progress 2014, 30 (5), 1103-1113.

33. Rakel, N.; Galm, L.; Bauer, K. C.; Hubbuch, J., Influence of macromolecular precipitants on phase behavior of monoclonal antibodies. Biotechnology Progress 2015, 31 (1), 145-153.

34. Ramsey, J. D.; Gill, M. L.; Kamerzell, T. J.; Price, E. S.; Joshi, S. B.; Bishop, S. M.; Oliver, C. N.; Middaugh, C. R., Using empirical phase diagrams to understand the role of intramolecular dynamics in immunoglobulin G stability. Journal of Pharmaceutical Sciences 2009, 98 (7), 2432-2447.

35. Reiche, K.; Hartl, J.; Blume, A.; Garidel, P., Liquid-liquid phase separation of a monoclonal antibody at low ionic strength: Influence of anion charge and concentration. Biophysical Chemistry 2017, 220, 7-19.

36. Annunziata, O.; Asherie, N.; Lomakin, A.; Pande, J.; Ogun, O.; Benedek, G. B., Effect of polyethylene glycol on the liquidliquid phase transition in aqueous protein solutions. Proceedings of the National Academy of Sciences 2002, 99 (22), 14165-14170. 37. Thompson Jr, R. W.; Latypov, R. F.; Wang, Y.; Lomakin, A.; Meyer, J. A.; Vunnum, S.; Benedek, G. B., Evaluation of effects of $\mathrm{pH}$ and ionic strength on colloidal stability of IgG solutions by PEG-induced liquid-liquid phase separation. The Journal of Chemical Physics 2016, 145 (18), 185101.

38. Jøssang, T.; Feder, J.; Rosenqvist, E., Photon correlation spectroscopy of human IgG. Journal of Protein Chemistry 1988, 7 
(2), 165-171.

39. Grimaldo, M.; Roosen-Runge, F.; Zhang, F.; Seydel, T.; Schreiber, F., Diffusion and Dynamics of Gamma-Globulin in Crowded Aqueous Solutions. The Journal of Physical Chemistry B 2014.

40. Forrer, N.; Butte, A.; Morbidelli, M., Chromatographic behavior of a polyclonal antibody mixture on a strong cation exchanger column. Part I: Adsorption characterization. Journal of Chromatography A 2008, 1214 (1), 59-70.

41. Forrer, N.; Butte, A.; Morbidelli, M., Chromatographic behavior of a polyclonal antibody mixture on a strong cation exchanger column. Part II: Adsorption modelling. Journal of Chromatography A 2008, 1214 (1), 71-80.

42. Stingaciu, L. R.; Ivanova, O.; Ohl, M.; Biehl, R.; Richter, D., Fast antibody fragment motion: flexible linkers act as entropic spring. Scientific Reports 2016, 6 .

43. Lilyestrom, W. G.; Shire, S. J.; Scherer, T. M., Influence of the cosolute environment on IgG solution structure analyzed by small-angle X-ray scattering. The Journal of Physical Chemistry B 2012, 116 (32), 9611-9618.

44. Chaves, R. C.; Teulon, J. M.; Odorico, M.; Parot, P.; Chen, S. w. W.; Pellequer, J. L., Conformational dynamics of individual antibodies using computational docking and AFM. Journal of Molecular Recognition 2013, 26 (11), 596-604.

45. Majumdar, R.; Manikwar, P.; Hickey, J. M.; Samra, H. S.; Sathish, H. A.; Bishop, S. M.; Middaugh, C. R.; Volkin, D. B.; Weis, D. D., Effects of salts from the Hofmeister series on the conformational stability, aggregation propensity, and local flexibility of an IgG1 monoclonal antibody. Biochemistry 2013, 52 (19), 3376-3389.

46. Galanti, M.; Fanelli, D.; Piazza, F., Conformation-controlled binding kinetics of antibodies. Scientific Reports $2016,6$.

47. Nel, R. G.; Oppenheim, S.; Rodgers, V., Effects of solution properties on solute and permeate flux in bovine serum albuminIgG ultrafiltration. Biotechnology Progress 1994, 10 (5), 539-542.

48. Cutler, P., Size-Exclusion Chromatography. In Protein Purification Protocols, Cutler, P., Ed. Humana Press: 2004; Vol. 244, pp 239-252.

49. Kralj, J. G.; Munson, M. S.; Ross, D., Total protein quantitation using the bicinchoninic acid assay and gradient elution moving boundary electrophoresis. Electrophoresis 2014, 35 (12-13), 1887-1892.

50. Zelic, B.; Nesek, B., Mathematical modeling of size exclusion chromatography. Engineering in Life Sciences 2006, 6 (2), 163 169.

51. Plebanski, M.; Burtles, S. S., In vitro primary responses of human T cells to soluble protein antigens. Journal of Immunological Methods 1994, 170 (1), 15-25.

52. Poplawska, M.; Bystrzejewski, M.; Grudziński, I. P.; Cywińska, M. A.; Ostapko, J.; Cieszanowski, A., Immobilization of gamma globulins and polyclonal antibodies of class igg onto carbon-encapsulated iron nanoparticles functionalized with various surface linkers. Carbon 2014, 74, 180-194.

53. Kitano, T.; Ateshian, G. A.; Mow, V. C.; Kadoya, Y.; Yamano, Y., Constituents and pH changes in protein rich hyaluronan solution affect the biotribological properties of artificial articular joints. Journal of Biomechanics 2001, 34 (8), 1031-1037.

54. Parkes, M.; Myant, C.; Cann, P. M.; Wong, J. S., Synovial fluid lubrication: The effect of protein interactions on adsorbed and lubricating films. Biotribology 2015.

55. Yousef, M.; Datta, R.; Rodgers, V., Free-solvent model of osmotic pressure revisited: application to concentrated IgG solution under physiological conditions. Journal of Colloid and Interface Science 1998, 197 (1), 108-118.

56. Balbo, J.; Mereghetti, P.; Herten, D.-P.; Wade, R. C., The shape of protein crowders is a major determinant of protein diffusion. Biophysical Journal 2013, 104 (7), 1576-1584.

57. Wasserman, R. L., A new intravenous immunoglobulin (BIVIGAM ${ }^{\text {) }}$ ) for primary humoral immunodeficiency. Expert Review of Clinical Immunology 2014, 10 (3), 325-337.

58. Jolles, S.; Sewell, W.; Misbah, S., Clinical uses of intravenous immunoglobulin. Clinical \& Experimental Immunology 2005, 142 (1), 1-11.

59. Hay, F. C.; Westwood, O. M., Practical immunology. John Wiley \& Sons: 2008.

60. Van Vaerenbergh, P.; Léonardon, J.; Sztucki, M.; Boesecke, P.; Gorini, J.; Claustre, L.; Sever, F.; Morse, J.; Narayanan, T. In An upgrade beamline for combined wide, small and ultra small-angle X-ray scattering at the ESRF, Proceedings of the 12th International Conference on Synchrotron Radiation Instrumentation - SRI2015, AIP Publishing: 2016; p 030034. 
61. Radulescu, A.; Szekely, N. K.; Appavou, M.-S., KWS-2: Small angle scattering diffractometer. Journal of Large-Scale Research Facilities 2015, 1, 29.

62. Zhang, F; Roosen-Runge, F.; Skoda, M. W.; Jacobs, R. M.; Wolf, M.; Callow, P.; Frielinghaus, H.; Pipich, V.; Prevost, S.; Schreiber, F., Hydration and interactions in protein solutions containing concentrated electrolytes studied by small-angle scattering. Physical Chemistry Chemical Physics 2012, 14 (7), 2483-2493.

63. Chen, S.-H.; Lin, T.-L., Colloidal Solutions. In Methods in Experimental Physics - Neutron Scattering, Elsevier Inc.: 1987; Vol. 23 B, pp 489-543.

64. Menon, S.; Manohar, C.; Rao, K. S., A new interpretation of the sticky hard sphere model. The Journal of Chemical Physics 1991, 95 (12), 9186-9190.

65. Kline, S. R., Reduction and analysis of SANS and USANS data using IGOR Pro. Journal of Applied Crystallography 2006, 39 (6), 895-900.

66. Gronski, P.; Bauer, R.; Bodenbender, L.; Kanzy, E.; Schmidt, K.; Zilg, H.; Seiler, F., On the nature of IgG dimers. I. Dimers in human polyclonal IgG preparations: kinetic studies. Behring Institute Mitteilungen 1988, (82), 127-143.

67. Tankersley, D. L.; Preston, M. S.; Finlayson, J., Immunoglobulin G dimer: an idiotype-anti-idiotype complex. Molecular Immunology 1988, 25 (1), 41-48.

68. Roux, K. H.; Tankersley, D. L., A view of the human idiotypic repertoire. Electron microscopic and immunologic analyses of spontaneous idiotype-anti-idiotype dimers in pooled human IgG. The Journal of Immunology 1990, 144 (4), 1387-1395.

69. Gronski, P.; Bauer, R.; Bodenbender, L.; Boland, P.; Diderrich, G.; Harthus, H.; Kanzy, E.; Kühn, K.; Schmidt, K.; Walter, G., On the nature of IgG dimers. II. Idiotype--anti-idiotype complexes of polyclonal and monoclonal origin: size distribution patterns and molecular geometries. Behring Institute Mitteilungen 1988, (82), 144-153.

70. Ban, N.; Escobar, C.; Garcia, R.; Hasel, K.; Day, J.; Greenwood, A.; McPherson, A., Crystal structure of an idiotype-antiidiotype Fab complex. Proceedings of the National Academy of Sciences 1994, 91 (5), 1604-1608.

71. Schwab, I.; Nimmerjahn, F., Intravenous immunoglobulin therapy: how does IgG modulate the immune system? Nature Reviews Immunology 2013, 13 (3), 176-189.

72. Berger, M.; McCallus, D. E.; Lin, C. S. Y., Rapid and reversible responses to IVIG in autoimmune neuromuscular diseases suggest mechanisms of action involving competition with functionally important autoantibodies. Journal of the Peripheral Nervous System 2013, 18 (4), 275-296.

73. Wymann, S.; Zuercher, A.; Schaub, A.; Bolli, R.; Stadler, B.; Miescher, S., Monomeric and Dimeric IgG Fractions Show Differential Reactivity Against Pathogen - Derived Antigens. Scandinavian Journal of Immunology 2011, 74 (1), 31-41.

74. Gronski, P.; Schridde, C.; Kanzy, E.-J., Off-rate and concentration diversity in multidonor-derived dimers of immunoglobulin G. Molecular Immunology 2007, 44 (10), 2528-2540.

75. Gronski, P., IgG dimers in multidonor-derived immunoglobulins: aspects of generation and function. Current Pharmaceutical Design 2006, 12 (2), 181-190.

76. Svergun, D.; Barberato, C.; Koch, M., CRYSOL-a program to evaluate X-ray solution scattering of biological macromolecules from atomic coordinates. Journal of Applied Crystallography 1995, 28 (6), 768-773.

77. Saphire, E. O.; Parren, P. W.; Pantophlet, R.; Zwick, M. B.; Morris, G. M.; Rudd, P. M.; Dwek, R. A.; Stanfield, R. L.; Burton, D. R.; Wilson, I. A., Crystal structure of a neutralizing human IGG against HIV-1: a template for vaccine design. Science 2001, 293 (5532), 1155-1159.

78. Estes, D. M.; Templeton, J. W.; Hunter, D. M.; Adams, L., Production and use of murine monoclonal antibodies reactive with bovine IgM isotype and $\mathrm{IgG}$ subisotypes (IgG1, IgG2a and IgG2b) in assessing immunoglobulin levels in serum of cattle. Veterinary Immunology and Immunopathology 1990, 25 (1), 61-72.

79. Konarev, P. V.; Volkov, V. V.; Sokolova, A. V.; Koch, M. H.; Svergun, D. I., PRIMUS: a Windows PC-based system for smallangle scattering data analysis. Journal of Applied Crystallography 2003, 36 (5), 1277-1282.

80. Kilàr, F.; Simon, I.; Lakatos, S.; Vonderviszt, F.; Medgyesi, G. A.; Závodszky, P., Conformation of human IgG subclasses in solution. European Journal of Biochemistry 1985, 147 (1), 17-25.

81. Eryilmaz, E.; Janda, A.; Kim, J.; Cordero, R. J.; Cowburn, D.; Casadevall, A., Global structures of IgG isotypes expressing 
identical variable regions. Molecular Immunology 2013, 56 (4), 588-598.

82. Petoukhov, M. V.; Konarev, P. V.; Kikhney, A. G.; Svergun, D. I., ATSAS 2.1-towards automated and web-supported smallangle scattering data analysis. Journal of Applied Crystallography 2007.

83. Petoukhov, M. V.; Franke, D.; Shkumatov, A. V.; Tria, G.; Kikhney, A. G.; Gajda, M.; Gorba, C.; Mertens, H. D.; Konarev, P. V.; Svergun, D. I., New developments in the ATSAS program package for small-angle scattering data analysis. Journal of Applied Crystallography 2012, 45 (2), 342-350.

84. Svergun, D., Determination of the regularization parameter in indirect-transform methods using perceptual criteria. Journal of Applied Crystallography 1992, 25 (4), 495-503.

85. Tian, X.; Langkilde, A. E.; Thorolfsson, M.; Rasmussen, H. B.; Vestergaard, B., Small - Angle X - ray Scattering Screening Complements Conventional Biophysical Analysis: Comparative Structural and Biophysical Analysis of Monoclonal Antibodies IgG1, IgG2, and IgG4. Journal of Pharmaceutical Sciences 2014, 103 (6), 1701-1710.

86. Lilyestrom, W. G.; Yadav, S.; Shire, S. J.; Scherer, T. M., Monoclonal antibody self-association, cluster formation, and rheology at high concentrations. The Journal of Physical Chemistry B 2013, 117 (21), 6373-6384.

87. Mosbæk, C. R.; Konarev, P. V.; Svergun, D. I.; Rischel, C.; Vestergaard, B., High concentration formulation studies of an IgG2 antibody using small angle X-ray scattering. Pharmaceutical Research 2012, 29 (8), 2225-2235.

88. Franke, D.; Svergun, D. I., DAMMIF, a program for rapid ab-initio shape determination in small-angle scattering. Journal of Applied Crystallography 2009, 42 (2), 342-346.

89. Volkov, V. V.; Svergun, D. I., Uniqueness of ab initio shape determination in small-angle scattering. Journal of Applied Crystallography 2003, 36 (3), 860-864.

90. Konarev, P.; Petoukhov, M.; Svergun, D., MASSHA-a graphics system for rigid-body modelling of macromolecular complexes against solution scattering data. Journal of Applied Crystallography 2001, 34 (4), 527-532.

91. Pettersen, E. F.; Goddard, T. D.; Huang, C. C.; Couch, G. S.; Greenblatt, D. M.; Meng, E. C.; Ferrin, T. E., UCSF Chimeraa visualization system for exploratory research and analysis. Journal of Computational Chemistry 2004, 25 (13), $1605-1612$.

92. Svergun, D.; Richard, S.; Koch, M.; Sayers, Z.; Kuprin, S.; Zaccai, G., Protein hydration in solution: experimental observation by x-ray and neutron scattering. Proceedings of the National Academy of Sciences 1998, 95 (5), 2267-2272.

93. Goldenberg, D. P.; Argyle, B., Self crowding of globular proteins studied by small-angle x-ray scattering. Biophysical Journal 2014, 106 (4), 895-904.

94. McNaught, A.; Wilkinson, A.; Nic, M.; Jirat, J.; Kosata, B.; Jenkins, A., IUPAC. Compendium of Chemical Terminology, 2nd ed. (the "Gold Book"). XML on-line corrected version: http://goldbook.iupac.org (2006-) Blackwell Scientific Publications: Oxford, 2000.

95. Roberts, D.; Keeling, R.; Tracka, M.; Van Der Walle, C.; Uddin, S.; Warwicker, J.; Curtis, R., Specific ion and buffer effects on protein-protein interactions of a monoclonal antibody. Molecular Pharmaceutics 2014, 12 (1), 179-193.

96. Saito, S.; Hasegawa, J.; Kobayashi, N.; Tomitsuka, T.; Uchiyama, S.; Fukui, K., Effects of ionic strength and sugars on the aggregation propensity of monoclonal antibodies: influence of colloidal and conformational stabilities. Pharmaceutical Research 2013, 30 (5), 1263-1280

97. Yan, Y.; Seeman, D.; Zheng, B.; Kizilay, E.; Xu, Y.; Dubin, P. L., pH-dependent aggregation and disaggregation of native $\beta$ lactoglobulin in low salt. Langmuir 2013, 29 (14), 4584-4593.

98. Yadav, S.; Laue, T. M.; Kalonia, D. S.; Singh, S. N.; Shire, S. J., The influence of charge distribution on self-association and viscosity behavior of monoclonal antibody solutions. Molecular Pharmaceutics 2012, 9 (4), 791-802.

99. Godfrin, P. D.; Zarraga, I. E.; Zarzar, J.; Porcar, L.; Falus, P.; Wagner, N. J.; Liu, Y., Effect of hierarchical cluster formation on the viscosity of concentrated monoclonal antibody formulations studied by neutron scattering. The Journal of Physical Chemistry B 2016, 120 (2), 278-291. 